\title{
Maintenance chrysotherapy in rheumatoid arthritis: a comparison of 2 dose schedules
}

\author{
A. J. GRIFFIN, ${ }^{1}$ T. GIBSON, ${ }^{1}$ G. HUSTON, ${ }^{1}$ AND A. TAYLOR ${ }^{2}$ \\ From ${ }^{1}$ Guy's Arthritis Research Unit, Guy's Hospital Medical School, London SE1 9RT, and the ${ }^{2}$ Department \\ of Biochemistry, University of Surrey, Guildford
}

SUMMARY Maintenance treatment with chrysotherapy was given to 44 rheumatoid patients after a total of $1.0 \mathrm{~g}$ weekly injections of sodium aurothiomalate. 21 patients continued with $50 \mathrm{mg}$ injections every 2 weeks and 23 patients received the same dose at 4 -week intervals. Their progress was followed over 1 year, after which time their clinical improvements were equally well sustained. Toxicity was greater in those patients receiving fortnightly injections. Five patients suffered a relapse after 8 months. These were not related to the frequency of injections nor to the serum gold levels. There appeared to be no advantage in maintenance injections at fortnightly intervals.

The value of gold salts as a treatment of rheumatoid disease is beyond dispute, and their more frequent and earlier use has been advocated. ${ }^{1}$ Conventionally, gold injections are administered weekly until a total of $1 \mathrm{~g}$ has been reached and thereafter at less frequent intervals. ${ }^{2}$ The importance of this maintenance period has been previously questioned, ${ }^{3}$ and the advantage over short courses was thought to be slight. ${ }^{+}$There is now compelling evidence that a more sustained improvement is obtained when (and indeed remission may not occur until) the patient has been receiving gold for 12 to 18 months. ${ }^{5}$

There is no consensus about the dose and frequency of gold injections needed to prevent relapse after $1 \mathrm{~g}$ has been given. It has been claimed that maintenance injections at 4-week intervals or longer are inadequate to maintain improvement ${ }^{6}$ and that serum gold levels must be kept above $300 \mu \mathrm{g} / \mathrm{dl}$ during this period for maximum clinical benefit. ${ }^{7}$

We have attempted to determine whether the response to maintenance gold injections given at 2-week intervals differs from the same dose administered every 4 weeks. In particular we have compared the clinical and radiological progression of the disease, the relative incidence of toxicity, and the relationship of serum gold level to relapse and side effects.

\section{Patients and methods}

Patients with rheumatoid arthritis were admitted to

Accepted for publication 1 August 1980

Correspondence to Dr T. Gibson. the study if they were receiving their first course of chrysotherapy, had shown a definite clinical improvement by the third month of treatment, and had developed no evidence of toxicity to gold. All patients had been given a test dose of $10 \mathrm{mg}$ sodium aurothiomalate, followed by weekly injections of $50 \mathrm{mg}$ to a total of $1 \mathrm{~g}$. Patients continued to receive nonsteroidal, anti-inflammatory agents throughout the study, and alterations other than reduction of dose on remission were avoided if possible. Intraarticular corticosteroid injections were given during the maintenance period only in emergency, though a number were given before a total of $1 \mathrm{~g}$ had been reached.

Patients were allocated randomly to the 2 maintenance dose schedules, each treatment group being stratified for age, sex, and $x$-ray score. Observations were made after 3,4 , and 5 months of weekly gold injections and then at 3-month intervals for 1 year. Observations made included the duration of early morning stiffness; the joint tenderness score ${ }^{8}$; grip strength recorded as the highest of 3 consecutive measurements; the total proximal interphalangeal joint circumference; and a count of peripheral nodules. The proximal interphalangeal joint circumference was measured with a single elasticated finger gauge supplied by the Geigy Company. $X$-rays of the hands and feet were obtained after $1 \mathrm{~g}$ of gold had been given and repeated after 6 months and 1 year of maintenance treatment. An $x$-ray score was obtained by counting the number of erosions as described by Sharp et al. ${ }^{9}$ The clinical evaluation and $x$-ray scores were performed by one 
of us (T.G.), who was unaware of the treatment group. In addition blood was taken at each assessment for haemoglobin, erythrocyte sedimentation rate, sheep cell agglutination titre, and serum gold, the last measured with a Perkin Elmer model 303 atomic absorption spectrophotometer.

\section{Results}

Fifty-eight patients were admitted to the study, but since 14 of these were withdrawn before or soon after $1 \mathrm{~g}$ had been reached the analysis was confined to 44 patients. All of these completed at least 6 months of maintenance treatment. Their treatment allocations and all essential clinical details are outlined in Table 1.

WITHDRAWALS FROM TREATMENT

Six patients failed to complete the maintenance period, 4 on the 2-weekly regimen and 2 on the 4-weekly regimen. Ten patients $(48 \%)$ receiving fortnightly injections and $5(22 \%)$ on the monthly injections developed toxicity. The relative frequency of adverse reactions is illustrated in Table 2.

\section{RELAPSES}

The majority of patients either maintained or increased the improvements gained during the period of weekly injections. Relapse, however, occurred in 5 patients after 8 to 11 months of maintenance therapy, 3 receiving 2 -weekly injections and 2 having 4-weekly injections. These patients were not characterised by any obvious clinical features, but 4 out of 5 were men. The mean and range of serum gold levels at 6 months were similar in those patients

Table 1 Clinical details of 44 patients who were followed up during 1 year of maintenance treatment

\begin{tabular}{lll}
\hline Treatment of regimen & 2 Weeks & 4 Weeks \\
\hline Number of patients & 21 & 23 \\
Sex & $12 \mathrm{~F} 9 \mathrm{M}$ & $16 \mathrm{~F} 7 \mathrm{M}$ \\
Mean age \pm SD & $54 \pm 9 \cdot 5$ & $55 \pm 11 \cdot 5$ \\
Disease duration \pm SD (years) & $5 \cdot 8 \pm 5 \cdot 0$ & $7 \cdot 0 \pm 5 \cdot 7$ \\
No. with nodules & 7 & 7 \\
Positive Rose-Waaler test & $11(52 \%)$ & $12(52 \%)$ \\
\hline
\end{tabular}

Table 2 The distribution and frequency of side effects on both dose schedules of chrysotherapy

\begin{tabular}{lcl}
\hline Treatment regimen & 2 Weeks & 4 Weeks \\
\hline Rash & 6 & 4 \\
Mouth ulcers & 3 & 1 \\
Proteinuria & 1 & - \\
Total & $10(48 \%)$ & $5(22 \%)^{*}$ \\
Withdrawals & 4 & 2 \\
\hline
\end{tabular}

${ }^{*} x^{2}=3 \cdot 27$, NS.
Table 3 Clinical details of patients who relapsed during maintenance treatment. Serum gold levels of relapsing and nonrelapsing patients after 6 months of maintenance therapy

\begin{tabular}{lll}
\hline Treatment regimen & 2 Weeks & 4 Weeks \\
\hline No. of patients relapsing & 3 & 2 \\
Sex & $3 \mathrm{M}$ & $1 \mathrm{M} \quad 1 \mathrm{~F}$ \\
Mean age & 59 & 46 \\
(range) & $(47-68)$ & $(34-58)$ \\
Mean serum gold & 160 & 91 \\
(range) $\mu \mathrm{g} / \mathrm{dl}$ & $(104-244)$ & $(69-113)$ \\
Mean serum gold of nonrelapsing patients & 108 & 118 \\
(range) $\mu \mathrm{g} / \mathrm{dl}$ & $(50-293)$ & $(65-195)$ \\
\hline
\end{tabular}

who relapsed and in those who sustained improvement (Table 3). The relapse was associated with an increase in rheumatoid factor titre in 1 patient, the remainder showing no change or a continued decline.

CLINICAL MEASUREMENTS

These are detailed in Table 4. In general, improvements achieved during the period of weekly injections were sustained during maintenance therapy in both treatment groups. Joint tenderness scores and grip strength showed a slight but progressive improvement over this period. The early morning stiffness tended to show an increase in the 2-weekly group maximal in the middle of the maintenance period and with a greater standard deviation than the 4-weekly group. The number of nodules decreased in only 2 patients, 1 in each group.

LABORATORY AND X-RAY MEASUREMENTS These are illustrated in Table 5. There was little change in haemoglobin values over the period of maintenance treatment. The mean sedimentation rates were identical after 1 year of maintenance therapy, though it appeared initially that the 2weekly group would continue to decline. A fall of rheumatoid factor titre was noted in 8 patients receiving 2-weekly injections and only 2 on the alternative regimen $\left(\chi^{2}=9.89 ; P<0.005\right)$. Three patients reverted to seronegativity on the more frequent dose and 2 on the 4-weekly injections. Serum gold levels fell dramatically with the introduction of maintenance therapy, and, surprisingly, there was a consistent but not significant difference in the levels of the $\mathbf{2}$ groups when receiving the same weekly dose. Consequently the fall of serum gold levels was more pronounced in those who received 4-weekly injections (Table 5).

Radiological deterioration occurred in 12 patients on the 2-weekly injections and in 11 on the 4-weekly injections; 19 of these deteriorated by only 1 to 5 erosions. Only 1 patient had marked worsening of his $x$-ray score (an increase of more than 10), and 
Table 4 Mean \pm standard deviation of clinical measurements before and during the period of maintenance treatment

\begin{tabular}{|c|c|c|c|c|c|c|c|c|}
\hline & \multirow{3}{*}{$\begin{array}{l}\text { Treatment } \\
\text { regimen } \\
\text { (weeks) }\end{array}$} & \multicolumn{7}{|c|}{ Months of treatment } \\
\hline & & \multicolumn{3}{|c|}{ Weekly injections } & \multicolumn{4}{|c|}{ Maintenance injections } \\
\hline & & 3 & 4 & 5 & 8 & 11 & 14 & 17 \\
\hline Early morning stiffness & $\begin{array}{l}2 \\
4\end{array}$ & $\begin{array}{l}28 \pm 44 \\
15 \pm 20\end{array}$ & $\begin{array}{l}27 \pm 41 \\
13 \pm 19\end{array}$ & $\begin{array}{l}25 \pm 38 \\
12 \pm 18\end{array}$ & $\begin{array}{l}25 \pm 55 \\
12 \pm 18\end{array}$ & $\begin{array}{l}41 \pm 67 \\
17 \pm 30\end{array}$ & $\begin{array}{l}46 \pm 78 \\
11 \pm 20\end{array}$ & $\begin{array}{l}35 \pm 52 \\
20 \pm 37\end{array}$ \\
\hline Joint tenderness score & $\begin{array}{l}2 \\
4\end{array}$ & $\begin{array}{l}7 \cdot 1 \pm 7 \cdot 1 \\
5 \cdot 3 \pm 3 \cdot 3\end{array}$ & $\begin{array}{l}6 \cdot 7 \pm 7 \cdot 5 \\
5 \cdot 1 \pm 4 \cdot 3\end{array}$ & $\begin{array}{l}7 \cdot 0 \pm 7 \cdot 7 \\
4 \cdot 7 \pm 3 \cdot 7\end{array}$ & $\begin{array}{l}6 \cdot 5 \pm 7 \cdot 3 \\
3 \cdot 7 \pm 3 \cdot 5\end{array}$ & $\begin{array}{l}6 \cdot 6 \pm 7 \cdot 8 \\
3 \cdot 5 \pm 3 \cdot 9\end{array}$ & $\begin{array}{l}5 \cdot 7 \pm 7 \cdot 7 \\
3 \cdot 2 \pm 3 \cdot 5\end{array}$ & $\begin{array}{l}6 \cdot 1 \pm 8 \cdot 5 \\
3 \cdot 2 \pm 2 \cdot 8\end{array}$ \\
\hline Grip strength: sum of & & & & & & & & \\
\hline 2 hands $(\mathrm{mmHg})$ & $\begin{array}{l}2 \\
4\end{array}$ & $\begin{array}{l}307 \pm 150 \\
281 \pm 141\end{array}$ & $\begin{array}{l}306 \pm 139 \\
289 \pm 121\end{array}$ & $\begin{array}{l}317 \pm 142 \\
291 \pm 137\end{array}$ & $\begin{array}{l}325 \pm 136 \\
296 \pm 138\end{array}$ & $\begin{array}{l}322 \pm 139 \\
299 \pm 135\end{array}$ & $\begin{array}{l}324 \pm 141 \\
307 \pm 141\end{array}$ & $\begin{array}{l}329 \pm 151 \\
314 \pm 140\end{array}$ \\
\hline $\begin{array}{l}\text { PIP joint circumference } \\
\text { (mm) }\end{array}$ & $\begin{array}{l}2 \\
4\end{array}$ & $\begin{array}{l}606 \pm 52 \\
574 \pm 44\end{array}$ & $\begin{array}{l}595 \pm 53 \\
572 \pm 45\end{array}$ & $\begin{array}{l}597 \pm 53 \\
583 \pm 49\end{array}$ & $\begin{array}{l}595 \pm 52 \\
571 \pm 42\end{array}$ & $\begin{array}{l}597 \pm 53 \\
566 \pm 42\end{array}$ & $\begin{array}{l}593 \pm 53 \\
570 \pm 43\end{array}$ & $\begin{array}{l}592 \pm 55 \\
572 \pm 45\end{array}$ \\
\hline
\end{tabular}

PIP = proximal interphalangeal.

Table 5 Mean \pm standard deviation of laboratory and radiological measurements before and during the period of maintenance treatment

\begin{tabular}{|c|c|c|c|c|c|c|c|c|}
\hline & \multirow{3}{*}{$\begin{array}{l}\text { Treatment } \\
\text { regimen } \\
\text { (weeks) }\end{array}$} & \multicolumn{7}{|c|}{ Months of treatment } \\
\hline & & \multicolumn{3}{|c|}{ Weekly injections } & \multicolumn{4}{|c|}{ Maintenance injections } \\
\hline & & 3 & 4 & 5 & 8 & 11 & 14 & 17 \\
\hline \multirow[t]{2}{*}{ Haemoglobin (g/dl) } & 2 & $13 \cdot 6 \pm 1 \cdot 4$ & $13 \cdot 3 \pm 1 \cdot 4$ & $13 \cdot 3 \pm 1 \cdot 7$ & $13 \cdot 5 \pm 1 \cdot 6$ & $13 \cdot 6 \pm 1 \cdot 8$ & $13 \cdot 4 \pm 1 \cdot 8$ & $13 \cdot 4 \pm 1 \cdot 2$ \\
\hline & 4 & $12 \cdot 3 \pm 1 \cdot 6$ & $12 \cdot 3 \pm 1 \cdot 0$ & $12 \cdot 4 \pm 1 \cdot 2$ & $12 \cdot 6 \pm 1 \cdot 1$ & $12 \cdot 7 \pm 1 \cdot 3$ & $12 \cdot 8 \pm 1 \cdot 7$ & $12 \cdot 8 \pm 1 \cdot 5$ \\
\hline \multirow[t]{2}{*}{$\operatorname{ESR}(\mathrm{mm} / \mathrm{h})$} & 2 & $27 \pm 22$ & $31 \pm 28$ & $27 \pm 21$ & $23 \pm 18$ & $23 \pm 28$ & $26 \pm 24$ & $27 \pm 22$ \\
\hline & 4 & $31 \pm 17$ & $28 \pm 18$ & $27 \pm 22$ & $27 \pm 19$ & $28 \pm 21$ & $25 \pm 22$ & $27 \pm 25$ \\
\hline \multirow[t]{2}{*}{ Serum gold $(\mu \mathrm{g} / \mathrm{dl})$} & 2 & $253 \pm 126$ & $251 \pm 122$ & $280 \pm 96$ & $112 \pm 96$ & $125 \pm 62$ & $127 \pm 58$ & $127 \pm 66$ \\
\hline & 4 & $384 \pm 80$ & $348 \pm 116$ & $350 \pm 119$ & $118 \pm 38$ & $89 \pm 37$ & $92 \pm 31$ & $97 \pm 37$ \\
\hline \multirow[t]{2}{*}{$X$-ray score } & 2 & - & - & $20 \pm 37$ & - & $21 \pm 37$ & - & $24 \pm 39$ \\
\hline & 4 & 一 & - & $19 \pm 20$ & 一 & $20 \pm 21$ & 一 & $21 \pm 21$ \\
\hline
\end{tabular}

he was receiving gold at 2 -week intervals. Improvement of 1 or more erosions appeared to occur in 5 patients, 3 of these on fortnightly injections.

\section{Discussion}

Our results suggest that maintenance sodium aurothiomalate in the dose of $50 \mathrm{mg}$ every 4 weeks is as effective as the same dose given at 2-week intervals. Clinical improvements achieved during the period of weekly injections were sustained equally well, and except in 5 patients who relapsed during maintenance therapy there was an overall improvement in grip strength and joint tenderness.

The higher serum gold levels obtained by more frequent injections did not confer any obvious symptomatic benefit. No patient had a serum gold level in excess of $300 \mu \mathrm{g} / \mathrm{dl}$ during maintenance treatment, and it is doubtful whether there is any advantage in maintaining levels above this value as advocated by Lorber et al. ${ }^{7}$ In our patients there was a considerable overlap of individual serum gold levels between the 2 maintenance treatment groups, but the mean level of those on 4-weekly injections was slightly lower. The latter group indicated a tendency to higher serum gold values during the period weekly injections, and there was no obvious explanation for this phenomenon.

There was an initial indication that more frequent maintenance injections were associated with a progressive decline in sedimentation rate, and in a preliminary report we speculated that this might imply a better clinical outcome. ${ }^{10}$ At the end of 1 year sedimentation rates were identical in the 2 groups, and our speculation was not substantiated. The larger number of patients with a reduction of rheumatoid factor titre following 2-weekly injections was not reflected in any clinical advantage in this group.

It was not possible to say whether the rate of radiological progression was retarded by maintenance injections. There was no difference between the two regimens in this respect, and, although five patients appeared to have an improved $x$-ray picture at the end of a year, the majority had deteriorated slightly. There is good evidence that chrysotherapy may modify or prevent erosive changes both in the early stages of the disease ${ }^{1}$ and over a longer period. ${ }^{11}$

Toxicity was greater in those patients receiving 2-weekly injections, though the differences were not statistically significant. Furst et al. ${ }^{12}$ noted a higher 
incidence of toxicity among patients receiving maintenance injections of $150 \mathrm{mg}$ of sodium aurothiomalate compared with a lower dose, but they did not indicate whether the risks were also accentuated by more frequent injections. They failed to observe any relationship between side effects and serum gold levels, and this is in accordance with previous studies. ${ }^{13} 14$

Our patients with the highest serum gold levels during maintenance treatment did not show an increased rate of side effects. The risk of gold toxicity diminishes with the duration of treatment but does not disappear completely. Kean and Anastassiades $^{15}$ have shown that, for those who remit, gold treatment may be continued for up to 3 years with an increasing margin of safety.

It was notable that 5 patients in our study relapsed after 8 months of maintenance treatment. These had all done well up to that time, though none had completely remitted, and there was no evidence that their deterioration was related to the frequency of maintenance injections or serum gold levels. Four of these patients were men, but whether the disparity of sex distribution has any relevance cannot be determined on the basis of such small numbers. A tendency for some patients to deteriorate after prolonged periods of remission and despite continued chrysotherapy has been previously reported. ${ }^{15}$ It has been argued that maintenance injections beyond the total of $1 \mathrm{~g}$ of gold salts cannot influence the outcome and that improvements gained during a period of weekly injections may persist for variable periods thereafter. ${ }^{3}$ This is not the conventional view, and the value of maintenance injections has been convincingly demonstrated. ${ }^{5}$ However, it is disquieting to note the report of Rothermich et al. ${ }^{16}$ in which it was stated that many patients who initially benefit from gold salts would deteriorate and that only $15 \%$ of patients continue with this treatment beyond 4 years. It is clear from our study that a maintenance dose of $50 \mathrm{mg}$ at 2-weekly intervals confers no benefit over $50 \mathrm{mg}$ per month and may enhance the risks of side effects. We made no attempt to determine iwhether relapses can be mitigated by recourse to more frequent injections or larger doses of gold, nor do we suggest that monthly injections provide the ideal regimen.

There is an urgent need for more thorough appraisal of different maintenance schedules of chrysotherapy.
We thank Dr R. Grahame and Professor C. Panayi for allowing us to study his patients.

\section{References}

1 Luukkainen R, Isomäki $H$, Kajander A. Effect of gold treatment on the progression of erosions in RA patients. Scand J Rheumatol 1977; 6: 123-7.

${ }^{2}$ Freyberg R H. Gold therapy for rheumatoid arthritis. In: Hollander J L, McCarty D J, eds. Arthritis and Allied Conditions. Philadelphia: Lea and Febiger, 1972: 455-82.

3 Cats A. A multicentre controlled trial of the effects of different dosages of gold therapy followed by a maintenance dosage. Agents Actions 1976; 6: 355-63.

4 Vorenkamp E P, de Blecourt J J. Gold treatment in rheumatoid arthritis. Abstracts of the VI European Rheumatology Congress, Brighton, 1971, Abstract 10.

5 Srinivasan R, Miller B L, Paulus H E. Long term chrysotherapy in rheumatoid arthritis. Arthritis Rheum 1979; 22: 105-10.

6 Gerber R C, Paulus H E. Gold Therapy. Clin Rheum Dis 1975; 1 : 307-18.

7 Lorber A, Atkins C J, Chang C C, Lee Y B, Starrs J, Bovy $R$ A. Monitoring serum gold values to improve chrysotherapy in rheumatoid arthritis. Ann Rheum Dis 1973; 32: 133-9.

8 Ritchie D M, Boyle J A, McInnes J M, et al. Clinical studies with an articular index for the assessment of joint tenderness in patients with rheumatoid arthritis. Q J Med 1968; 37: 393-406.

9 Sharp J T, Lidsky M D, Collins L C, Moreland J. Methods of scoring the progression of radiological changes in rheumatoid arthritis. Arthritis Rheum 1971; 14: 706-20.

10 Griffin A J, Gibson T, Taylor A. Comparison of two maintenance schedules of chrysotherapy in rheumatoid arthritis: preliminary report. Rheumatol Rehabil 1978; 17 (suppl): 99-104.

11 Sigler J W, Bluhm G B, Duncan H, Sharp J T, Ensign D C, McCrum W R. Gold salts in the treatment of rheumatoid arthritis: A double-blind study. Ann Intern Med $1974 ; 80: 21-6$.

12 Furst D E, Levine S, Srinivasan R, Metzger A, Bangert R, Paulus H E. Double-blind trial of high versus conventional dosages of gold salts for rheumatoid arthritis. Arthritis Rheum 1977; 20: 1473-80.

13 Billings R, Grahame R, Marks V, Wood P J, Taylor A. Blood and urine gold levels during chrysotherapy for rheumatoid arthritis. Rheumatol Rehabil 1975; 14: 13-8.

14 Jessop J D, Johns R G S. Serum gold determinations in patients with rheumatoid arthritis receiving sodium aurothiomalate. Ann Rheum Dis 1973; 32: 228-32.

15 Kean W F, Anastassiades T P. Long term chrysotherapy: incidence of toxicity and efficacy during sequential time periods. Arthritis Rheum 1979; 22: 495-501.

16 Rothermich ${ }^{\top}$ N O, Philips V K, Bergen W, Thomas M H. Follow-up study of chrysotherapy. Arthritis Rheum 1979; 22: 423 . 